\title{
Magnitude of reward in selective learning'
}

JOHN H. MORRISON AND JOHN J. PORTER

UNIVERSITY OF WISCONSIN-MILWAUKEE

\begin{abstract}
The growth of incentive motivation was investigated in a two choice discrimination using three groups of $10 \mathrm{Ss}$ for 300 trials. The experimental group was trained with $20 \mathrm{mg}$ and $97 \mathrm{mg}$ rewards. One control group received $20 \mathrm{mg}$ while the other control received $97 \mathrm{mg}$ on all trials. Asymptotic running speed was not achieved, but the converging speeds of the control groups tended to support the "habit" hypothesis. Both a negative contrast effect, where the experimental Ss ran slower to $20 \mathrm{mg}$ than did the controls, and a positive contrast effect, where the experimental Ss ran faster to $97 \mathrm{mg}$ than did the controls, was observed.
\end{abstract}

\section{Problem}

For Hull (1952) and Spence (1956), incentive motivation (K) has been assumed to be a function of the classically conditioned consummatory habit $\left(\mathrm{r}_{\mathrm{g}}\right)$. It follows that a large reward leads to more rapid growth of $\mathbf{r}_{\mathbf{g}}$ (and thus $\mathrm{K}$ ) than a small reward, since, on each trial, the consummatory response is practiced more often when ingesting a large reward. However, when the $\mathbf{r}_{\mathbf{g}}$ habit to the small reward reaches asymptote, performance should be the same to both small and large reward. Thus, the rate of performance increase depends on reward magnitude, while the asymptote of performance does not (Spence, 1956, 140-141).

Both Hull and Spence considered the alternative that different rewards might produce different $\mathbf{r}_{\mathbf{g}} \mathbf{s}$, rather than different rates of learning the same $r_{g}$. Spence (1956, 142-148) assumed that the "vigor" of the consummatory response, rather than the amount of practice, determined incentive motivation (K). Thus, the "vigor" hypothesis, in contrast to the "habit" hypothesis, predicts that the asymptote of performance is a function of the magnitude of reward. Most studies of magnitude of reward seem to favor the "vigor" hypothesis over the "habit" hypothesis (cf.: Festinger, 1943; Davenport, 1964). However, the "habit" hypothesis has not really been tested since none of the relevant studies have used enough trials to assure asymptotic performance.

Selective learning studies contrasting differential reward magnitudes have suggested that running speed is not a simple function of magnitude of reward, but is rather a function of the difference between two rewards. This "contrast effect" has been observed by Bower (1961), Porter (1964), Clayton (1965), and Spear \& Hill (1965).

The present study attempted to answer two questions about contrast effects and the "vigor" and "habit" hypotheses in selective learning: With other factors held constant does magnitude of reward determine response speed and choice behavior, or are reward effects temporary, with amount of practice of the consummatory response determining final asymptotic performance? Are constant effects temporary or permanent obstructions which mask the simple effects of reinforcement?

\begin{abstract}
Method
Thirty naive female hooded rats, 180 days old when training began, were used. Ss were run in a wedge-shaped choice chamber, similar to that used by Ramond (1954), which was 12-in deep and 18-in wide at the goal end. The chamber had retractable response levers on either side, illuminated by a shielded 7-watt bulb such that each lever was illuminated by the light above it. On free choice trials both lights were on and both levers were in the chamber. On forced trials, only one lever was in the chamber and one light was on. Ss were timed from the opening of the start box glass door until $S$ actuated a contact relay by touching the bar.

The Ss were assigned to three groups of 10 each, one experimental group and two control groups. The experimental group received a $97 \mathrm{mg}$ Noyes pellet to the large reward side and a $20 \mathrm{mg}$ pellet to the small reward side. Both control groups received equal reward to both sides of the chamber, the small reward group $20 \mathrm{mg}$ and the large reward group $97 \mathrm{mg}$. One half of the $\mathrm{Ss}$ in the 97-20 group were assigned their large reward to their preferred side to balance position preferences. For five weeks before the experiment began, Ss were allowed $1 \mathrm{hr}$. free access to food after $23 \mathrm{hr}$. deprivation. During this period, each $S$ was handled for $5 \mathrm{~min}$. daily. For three days prior to the actual training, Sis were allowed $5 \mathrm{~min}$. exploration of the apparatus. All Ss received four such exposures daily. On half of the exploratory trials a pellet was placed on the left side of the chamber, the remainder of the time on the right. The experimental Ss received $97 \mathrm{mg}$ on half of these trials and $20 \mathrm{mg}$ on the remaining trials. Although the levers were not in the chamber during this phase of training, both 7-watt bulbs were on.

Following pretraining, Ss received six trials a day for four days, 12 trials a day for two days, and 18 trials a day thereafter. The Ss were run one group at a time. After a block of six trials Ss were returned to their home cages. In each block of six trials the sequence of choice and forced trials was CCFFFF. Response speeds were measured on the last two forced trials in each block of six. On the 18 trials per day schedule Ss were forced twice to the large reward on the fifth trial of one day and forced twice to the large reward on the sixth trial the next day.
\end{abstract}

\section{Results}

The mean speeds of the control groups and of the experimental group to both $97 \mathrm{mg}$ and $20 \mathrm{mg}$ appear in Fig. 1, plottted in 5 blocks of 6 trials to each discriminanda. The points on the curves represent mean speeds after $60,120,180,240$, and 300 trials.

Comparing the speeds of the experimental Ss to 20 $\mathrm{mg}$ with the speeds of the two control groups demonstrated that performance depended upon both magnitude of reward, $F(2,27)=4.69, p<.05$, and number of trials, $F(4,108)=74.95, p<.001$. A significant interaction between these variables, $F(8,108)=6.95, p<.001$, demonstrated the changing relationship between the speeds of the experimental and control groups over trials, and prompted comparisons of the mean speeds between 


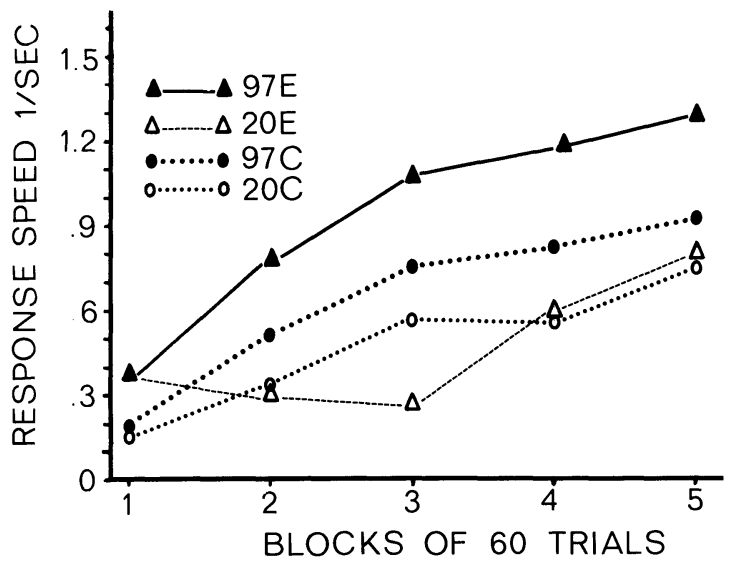

Fig. 1. Mean speeds after each block of 60 trial for the two control groups (C) and the experimental group (E). Each point on the figure represents the mean of 20 forced trials ( 10 per side) for the control groups, and $\mathbf{1 0}$ forced trials to the $\mathbf{9 7} \mathrm{mg}$ side and $\mathbf{1 0}$ forced trials to the $20 \mathrm{mg}$ side for the experimental groups.

groups at different stages of training. The critical difference (CD) for all comparisons (Cochran \& Cox, 1950) was calculated: $\mathrm{CD}(26,107)=0.195, \mathrm{p}=.05$. After 180 trials the mean speed of the experimental Ss to 20 mg was significantly less than the speed of the 20-20 Ss, $\mathrm{p}=0.271$. After 240 trials a reversal of this trend occurred, increasing through 300 trials, although neither trend reached significance. The 97-97 control group was faster to $97 \mathrm{mg}$ than the experimental Ss to $20 \mathrm{mg}$ after 180 trials, $\mathrm{D}=0.459$; and 240 trials, $\mathrm{D}=0.210$. However, after 300 trials this difference was not significant. After 240 trials the 97-97 control group was running faster than the 20-20 control group, $\mathrm{D}=0.242$; however, after 300 trials the two control groups did not differ significantly in speed.

Analyzing the speeds to $97 \mathrm{mg}$ of the experimental group and the speeds of the control groups yielded a significant increase in speed over trials, $F(4,108)=108.55$, $\mathrm{p}<.001$. The interaction between magnitude of reward and trials was also significant, $F(8,108)=11.50, p<.001$. Again the method of Cochran and Cox was used to compare the mean speeds of the three groups at different stages of training. This time the $\operatorname{CD}(26,107)=0.237$, $\mathrm{p}=.05$. The experimental Ss ran faster to $97 \mathrm{mg}$ than the 97-97 control group after 120 trials, $\mathrm{D}=0.243$, and continued to do so throughout training. The greater speed of the experimental Ss was even more apparent when compared with the 20-20 Ss. After 120 trials $\mathrm{D}=0.408$, and at the end of training $\mathrm{D}=0.535$.

The large difference between speeds to $97 \mathrm{mg}$ and $20 \mathrm{mg}$ for the experimental Ss proved highly significant, $F(1,9)=104.77, p<.001$, as did the magnitude of reward by trials interaction, $\mathrm{F}(4,36)=8.14, \mathrm{p}<.001$, reflecting the initial decrement in speed to the $20 \mathrm{mg}$ reward. Percentage choice of the $97 \mathrm{mg}$ reward reached $100 \%$ by the 84 th trial and remained at $100 \%$ for the remainder of training. The control group went to each side approximately $50 \%$ of the time.

\section{Discussion}

By using single $20 \mathrm{mg}$ and $97 \mathrm{mg}$ pellets as rewards, and removing each $\mathrm{S}$ immediately after ingesting a reward, Spence's (1956, 137-142) qualifications for a clear test of the "vigor" and "habit" hypotheses about the effects of magnitude of reward in two-choice selective learning were satisfied. The convergence of the two control group speeds at 300 trials lends some tentative support to the "habit" hypothesis. However, the contrast effects present in the experimental group data prevented using their speeds when examining the evidence for the "vigor" and "habit" hypotheses.

A negative contrast effect, defined by the slower speeds of the experimental Ss to $20 \mathrm{mg}$ compared to the control Ss, appeared to be the result of a conditioned emotional response similar to that observed in studies of frustration (cf.: Amsel, 1958). This interpretation resulted from observing that the experimental Ss, when receiving $20 \mathrm{mg}$ on forced trials, ran to the dark side of the chamber (the $97 \mathrm{mg}$ nonreward side) more than twice as often as the control Ss.

A positive contrast effect, defined by the faster speeds of the experimental group to $97 \mathrm{mg}$ compared to the $97 \mathrm{mg}$ controls, was clearly evident during training, and its magnitude was still increasing at the end of training. This fact, coupled with the reversal of the negative contrast effect late in training (after trial 180), indicated that a great deal of additional training would be needed to determine if the observed contrast effects were temporary emotional effects, or a permanent behavioral change.

\section{References}

Amsel, A. The role of frustrative nonreward in noncontinuous reward situations. Psychol. Bull., 1958, 55, 102-119.

Bower, G. H. A contrast effect in differential conditioning. J. exp. Psychol., 1961, 62, 196-199.

Clayton, K. N., T-maze choice learning as a joint function of the reward magnitudes for the alternatives. J. comp. physiol. Psychol., 1965, in press.

Cochran, W. G., \& Cox, G. M. Experimentai designs. New York: John Wiley and Sons, 1950. Pp. 92-93.

Davenport, J. W. The interaction of magnitude and delay of reinforcement in spatial discrimination. J. comp. physiol. Psychol., $1964,55,267-273$.

Festinger, L. Development of differential appetite in the rat. $J$. exp. Psychol., 1943, 32, 226-234.

Hull, C. L. A behavior system. New Haven: Yale University Press, 1952.

Porter, J. J. Effects of differential reward magnitudes on simple brightness discrimination with free and forced trials. Psychol. Rep., 1964, 15, 279-286.

Ramond, C. K. Performance in selective learning as a function of hunger. J. exp. Psychol., 1954, 48, 265-270.

Spear, N. E., \& Hill, W. F. Adjustment to new reward: Simultaneous and successive contrast effects. J. exp. Psychol., 1965, in press.

Spence, K. W. Behavior theory and conditioning. New Haven: Yale University press, 1956 .

Note

1. This experiment is based upon the first author's Master Thesis under the direction of the second author. 